\title{
Problem-Solving Argumentative Patterns in Plenary Debates of the European Parliament
}

\author{
Bart Garssen ${ }^{1}$
}

Published online: 30 September 2015

(C) The Author(s) 2015. This article is published with open access at Springerlink.com

\begin{abstract}
The aim of this paper is to describe the way in which argumentative patterns come into being in plenary debate over legislative issues in the European Parliament. What kind of argumentative patterns are to be expected within this macro context? It is shown that the argumentative patterns that come into being in legislative debate in the European Parliament depend for the most part on the problem-solving argumentation that is put forward in the opening speech by the rapporteur of the parliamentary committee report. This argumentation can be pragmatic problem-solving argumentation or complex problem-solving argumentation. The most important prototypical argumentative patterns are investigated in the argumentation put forward by the Members of parliament. This investigation is based on an inventory of the arguments that can in principle be used to support or attack the initial problem-solving argumentation put forward by the rapporteur.
\end{abstract}

Keywords European Parliament - Legislation - Parliamentary debate · Pragmatic argumentation $\cdot$ Problem-solving argumentation

\section{Introduction}

In the last two decades the European Parliament has become an import factor in the legislative process of the European Union. Together with the Council, Parliament can approve, amend or reject proposals for legislation put forward by the Commission. In the legislative process the parliamentary debates have a fixed place

Bart Garssen

b.j.garssen@uva.nl

1 Department of Speech Communication, Argumentation Theory and Rhetoric, University of Amsterdam, Spuistraat 134, 1012 VB Amsterdam, The Netherlands 
and function since Members of the European Parliament (MEP's) vote on Commission proposals after these proposals are discussed in plenary sessions.

The aim of this paper is to describe the way in which argumentative patterns come into being in plenary debate over legislative issues in the European Parliament. What kinds of argumentative patterns are to be expected within this context and what kind of argumentative patterns are most likely to be used by MEP's, given the institutional aim of the activity type?

In their comprehensive research project in which they examine the institutional preconditions for strategic maneuvering in legislative debate in the European Parliament (van Eemeren and Garssen 2010, 2011) van Eemeren and Garssen have characterized the legislative debate as an argumentative activity type. They come to the conclusion that the debates in the European Parliament are on the one hand highly regulated: there is a fixed speaking order and there is not much room for interruption. This makes parliamentary debates quite organized and structured. On the other hand, there are not many limitations when it comes to the types of argumentation that can be used by MEP's.

There are no special constraints as to the argument schemes that can be employed in the argumentation stage. However, the types of argumentation that are actually employed in European parliamentary debates are largely determined by the fact that the debate is a political debate dealing with legislation and policy matters (van Eemeren and Garssen 2010, p. 30). ${ }^{1}$

The types of argumentation that can be used by proponents and opponents is for the most part predetermined by the initial presentation by the rapporteur. Since the institutional aim of the activity type of legislative debate in the European Parliament is sustained opinion forming on a proposal for legislation, the main type of argument that is to be expected is practical argumentation that is presented directly at the beginning of the debate by the opponent. This practical argumentation is always aimed at solving a certain problem. The argumentation put forward by the MEP's will have to be relevant to this initial argumentation.

In this paper I will therefore first give an account of the problem-solving argumentation put forward by the rapporteur. Next, I will make a systematic inventory of the argument schemes that can be used by the proponents to support the initial problem-solving argumentation and of the argument schemes that can be used by the opponents to attack the initial problem-solving argumentation.

Subsequently, I will describe the prototypical argumentative patterns that most likely come into being in legislative parliamentary debate. Since there is no institutional regulation when it comes to the argument schemes that may be used in the debate, this effort is based on strategic considerations: what kind of argumentative patterns are MEPs most like to use in their efforts to be as effective as possible?

\footnotetext{
1 There is not one type of debate in the European Parliament. Some of these debates are on legislation (first reading and second reading), other debates concern statements by the Commission or oral questions to the or the Council, still others are, for instance, on human rights in non-European countries or on other issues relevant to the European Parliament. I will focus on legislative debates on Commission proposals (first and second readings).
} 


\section{The Structure of Legislative Debate in the European Parliament}

Since the 1990s, through the Maastricht, Amsterdam and Nice Treaties the European Parliament can be considered co-legislator, sharing legislative power with the Council across the majority of policy areas (Corbett et al. 2007, p. 205). With the introduction of the co-decision procedure European Parliament gained considerable influence on legislation.

The shortest route to legislation is as follows: Parliament decides on a commission proposal and comes with a first reading "opinion" approving the (amended) proposal. If the Council agrees with this opinion the legislative proposal is adopted. In case the Council does not approve the outcome of the EP first reading, it adopts a "common position". In the second reading Parliament may approve this common position, it may adopt amendments or it may reject the common position by an absolute majority of its members (Corbett et al. 2007, p. 217).

In practice, the parliamentary work is organized through a system of standing and temporary committees that are responsible for the preparatory work for plenary parliamentary sittings. The committees draw up, adopt and amend legislative proposals as well as own-initiative reports, consider Commission and Council proposals and, where necessary, prepare reports to be presented to the plenary assembly. Much of their time the committees spend drawing up reports on legislation that is proposed by the Commission, but they can also draw up "owninitiative reports" on issues that fall within the scope of the committee's competence (van Eemeren and Garssen 2010, p. 27).

In legislative debate in the European Parliament, there is a fixed order of debate turns. The order of turns is as follows. The rapporteur of the committee involved starts with a statement, which may take up to $6 \mathrm{~min}$. After this, a Member of the Commission reports on the reasons for the Commission to initiate the legislative procedure or on the Commissions' view on proposed amendments. If a member of the Council is present, he may speak as well. Subsequently MEP's of all political groups are given the opportunity to react to the report. Finally, the Member of the Commission will indicate its position on specific amendments tabled in the report before Parliament (Corbett et al. 2007, p. 174). Usually the rapporteur closes the debate with some final statements reacting to the opinions put forward by the Members of parliaments. The following list represents the general of the order of turns in legislative debates ${ }^{2}$ :

1. Opening statement by the rapporteur

2. Opening statement by the Member of the Commission

3. Main Group spokespersons for the issue (Members of Parliament)

4. Individual turns by Members of Parliament

5. Closing statement by the Member of the Commission

6. Closing statement by the rapporteur

\footnotetext{
${ }^{2}$ If Council members are present, they may speak as well at the beginning and sometimes at the of the debate.
} 
After the opening by the rapporteur the actual debate develops. Legislative debates consist of a series of reactions to the report as it is presented by the rapporteur. This is why the presentation by the rapporteur is pivotal for understanding the overall structure of the argumentation put forward.

When Parliament receives a formal Commission or Council proposal (common opinion), a parliamentary committee writes a report on the proposal. In legislation or regulative debates the 'rapporteur' chosen by the committee gives a brief description of the report that was made to present the proposal for legislation. The rapporteur also presents the proposal or the amended proposal prepared by the committee. In a great many cases the rapporteur includes some information about the process that leads to the report: it took a long time to prepare, a great many parties had to satisfied, etc. In this description the rapporteur may also refer to amendments that had to be made on earlier versions of the legislation.

The rapporteur will provide argumentation supporting the main standpoint that the proposed legislation or an amended version of the proposal should be accepted. Defending this inciting standpoint calls for practical argumentation. Practical argumentation is argumentation that is put forward to defend a standpoint that expresses a plan, policy or, more general a certain action that should be performed or not be performed.

In the initial argumentation that is presented in the report, the committee concerned always points at a certain problem that need to be solved. In his or her opening speech the rapporteur presents the problem as the main reason why new legislation is needed. That is why the main arguments for the inciting standpoint that the legislation should be adopted centre around the idea that implementing the new legislation will solve the problems. The main argumentation of the rapporteur can thus be called problem-solving argumentation.

\section{Problem-Solving Argumentation}

Since the deliberation in the European Parliament is always about solving a specific problem the main argumentation that is put forward will be practical in nature. Generally speaking practical argumentation involves pointing at positive of negative causal consequences of a certain policy or plan. ${ }^{3}$ In this case it is the positive consequence of solving or help solving the problem that is mentioned: the proposed legislation should be adopted because it will remove the predicament that is mentioned in the proposal.

Two types of practical argumentation are to be expected in the opening statement by the rapporteur: pragmatic problem-solving argumentation and complex problemsolving argumentation. The first type is straightforward pragmatic argumentation in which the proposal is defended by pointing at the positive results of implementing the proposal: because adopting the proposal leads to the favourable results (the

\footnotetext{
3 Although in most cases it is, practical argumentation does not need to be causal in nature. A non-causal type of practical argumentation is argumentation in which it is pointed out that the desired action or policy is in line with a certain normative behavioural rule. Another type of non-causal practical argumentation is argumentation based on a model, in which the arguer points to a person who's behaviour should be seen as an example (Perelman and Olbrechts-Tyteca p. 363).
} 
problems will be solved) we should adopt it. In this case it is presumed in the initial argumentation that the results are indeed positive. This means that the speaker takes it that there is no discussion about the favourableness of the intended results: there is at least one problem and this problem needs to be solved.

In the basic scheme of pragmatic argumentation (as described in the introduction to this special issue by van Eemeren) the proposed action leads to an unspecified positive (or negative) result:

\section{Basic argument scheme of pragmatic argumentation}

1. Standpoint Action X should be carried out

1.1 Action $\mathrm{X}$ will lead to positive result $\mathrm{Y}$

(1.1') (Actions of type $X$ [such as $\mathrm{X}$ ] that lead to positive results of type $Y$ [such as $\mathrm{Y}$ ] must be carried out)

The implementation of this scheme in the context parliamentary debate leads to the following specification.

\section{Pragmatic problem-solving argumentation}

1 The proposed legislation $\mathrm{X}$ should be adopted

1.1 Adoption of the proposed legislation $\mathrm{X}$ solves problem $\mathrm{Y}$

(1.1' Proposed legislation [of type X] that solves the problem [of type Y] should be adopted)

In pragmatic problem solving argumentation of argumentation it is clear from the outset that there is a problem and that the removal of the problem is a positive thing. The speaker does not need to convince the listener that these problems exist and that these problems need to be solved. These are in order words presuppositions that do not need any further argumentation.

In some cases the rapporteur just points at the favourable consequences of a measure. Although it is clear that the measure is meant to solve certain problems, these problems are is it were presented as a given. This may be because it is obvious or because in earlier debates it has already been settled that there is a problem, for instances in first readings of a Commission proposal.

A case in point is the debate on food labelling on 5 July 2011 in which rapporteur Renate Sommers presents at the opening the main arguments for food labelling:

\section{July 2011, Renate Sommers (Rapporteur)}

This regulation is intended to give consumers more and better information about food, in order to allow them to make informed purchasing decisions. That is not all, however. It should also benefit the European food industry by providing more legal certainty, less red tape and better law making.

It is striking that in this example more effects are mentioned: the legislation discussed will not only solve problems that consumers experience but also problems 
the food industry is faced with. The arguer relies in this case on a series of pragmatic arguments which are connected with each other in a coordinative argumentation structure. Although pragmatic arguments can also consist of pointing to just one favourable consequence, in argumentation in the European Parliament quite often more than just one consequence is mentioned. ${ }^{4}$

In other cases the rapporteur not only mentions the intended results of the proposal but also tries to make clear that the intended effects are indeed desirable. If it is necessary to argue for the desirability of the intended effects, straightforward pragmatic argumentation for the proposal is not enough because using this argument scheme presupposes that the audience is in agreement with the desirability of the effects of the proposal. Since this precondition is not always fulfilled, the rapporteur may need to address the question of desirability. In this case the rapporteur (and other MEP's) first need to convince their audience that there is a problem. This calls for a different type of practical argumentation.

In the second type of practical argumentation it is first established that there is a problem in the current situation, because this is not automatically accepted by the audience. The proposal is defended by showing that there is a problem and by stating that the implementation of the legislation will remove of will help removing the problem. This argumentation boils down at the following argumentative pattern that minimally consists of complementary coordinative argumentation in which the argument that there is a problem is defended by subordinate argumentation. This argumentative pattern, which is very close to pragmatic argumentation, will be called complex problem-solving argumentation:

\section{Complex problem solving argumentation}

$\begin{array}{ll}1 & \text { The proposed legislation } \mathrm{X} \text { should be adopted } \\ 1.1 \mathrm{a} & \text { There is a problem } \mathrm{Y} \\ 1.1 \mathrm{~b} & \text { Adoption of the proposed legislation } \mathrm{X} \text { will solve the problem } \\ (1.1 \mathrm{a}-1.1 \mathrm{~b} \text { ') } & \text { (Proposed legislation [of type } \mathrm{X} \text { ] that solves the problem [of type } \\ & \mathrm{Y} \text { ] should be adopted) }\end{array}$

The problem statement 1.1a is compound: it includes a descriptive and a normative component. First, there is the presupposition that a certain situation exists. I will call this the existential presupposition of the problem statement. Second, it involves the normative qualification that this situation is in some way unwanted or troublesome. I will call this the normative qualification of the problem statement. The significance of the problem depends both on the existential presupposition: 'how widespread is the problem?', and the normative presupposition: 'how unwanted is this situation?'.

It is more likely that this kind of argumentation is employed in parliamentary debate than simple pragmatic argumentation because it will not often be the case

\footnotetext{
${ }^{4}$ From the perspective of strategic manoeuvring, the choice that is made here is quite understandable. The author of the report has to takes several parties with different interests into account and maximizes in this way adaption to audience demand. In this case, no further argumentation is provided. Apparently when putting forward this pragmatic argument it was already understood that all involved are in favour of informed purchasing decisions, more legal certainty, less red tape, and better law-making.
} 
that all discussants are in full agreement that there is a problem and that this problem needs to be solved.

An example of such argumentation is the following part of the opening statement by Vidal-Quadras, in a debate on the proposal for a regulation of the European Parliament and of the Council concerning measures to safeguard security of gas supply.

\section{September 2010, Alejo Vidal-Quadras (Rapporteur)}

$\mathrm{Mr}$ President, in recent years, we have witnessed repeated examples of the vulnerability of Member States with respect to energy matters, particularly as regards the gas supply. Supply disruptions in the north and east of the European Union in the winters of 2005-2006 and 2008-2009 became a veritable nightmare. The harshness of recent winters in Europe makes it even more incumbent upon us, if possible, to do everything that is in our power to avoid similar occurrences in the future. [...] The regulation we are going to vote on is intended to be a firm step forward in resolving this problem. We have spent a long time trying to make progress on this issue, overcoming the difficulties arising from the different national perspectives. It has been a long and hard negotiation process.

Vidal-Qudras not only claims that the proposal will be effective ('a firm step forward in resolving this problem'), he also points explicitly at the problem to be solved (vulnerability of Member States with respect to energy matters) and provides even some examples that serve as support for the problem claim.

\section{Argumentation Used to Defend Problem-Solving Argumentation}

There are no institutional constraints to the types of argumentation that can be put forward in the debate. The official rules for the debate contain no limiting conditions, nor does the parliamentary debate tradition in any way impose restrictions to the use of certain types of argumentation. This means that the only restricting factor is that the argumentation should be relevant to standpoint and the initial practical argumentation put forward by the rapporteur.

In order to make some educated guesses about what kind of argumentative patterns can be expected, it is first necessary to make an inventory of the kind of arguments that the MEPs may use to defend or attack the initial practical argumentation.

Subordinate argumentation put forward in defence of parts of the original argumentation, can be seen as anticipation to criticism from an antagonist. Therefore, in order to systematically explore the possible extensions of the initial practical argumentation it is necessary to determine the critical questions pertaining to the two types of practical argumentation.

Because the two types of practical argumentation come with exactly the same sets of critical questions, and because complex problem-solving argumentation is more explicit than pragmatic argumentation, I will focus on complex problemsolving argumentation. A useful source for the critical questions that should be 
asked in evaluating complex problem-solving argumentation is the system of stock issues that is used American academic debate.

In American debate textbooks stock issues are proposed that are related to the defence of policy statements. Stock issues are the issues that the affirmative side in a debate has to address in defence of the proposition. If the affirmative side in a debate fails to deal with one of the stock issues effectively, the affirmative side loses.

Stock issues are part of the procedure for the distribution of the burden of proof in an academic (policy) debates. However, because they are systematically linked with problem-solving argumentation, they can be helpful in tracing the most important evaluative are relevant for Parliamentary debate as well.

Most textbooks mention four stock issues (ill, blame, cure and cost). ${ }^{5}$ However for my purposes I use the more comprehensive list of six stock issues proposed by Klopf and McCroskey (1969, p. 66-68), who add two issues (practicality and counterplan) to the original four:

1. Problem or need (ill): 'Is there a problem in existence which needs to be solved'? The affirmative has to establish that there is a problem. This can be a current problem or a problem that is likely to develop in the future (Ihnen 2012, p. 41).

2. Inherency (blame): 'Is the problem, or the cause of the problem, an inherent part of the status quo?' The affirmative has to show that the problem is caused by the current regulations or system and that without adopting the proposed policy, the problem will continue to exist in the future. '[...] The affirmative must prove that the significant harm it identifies is built into the essential nature of the status quo through legal structures and/or societal attitudes' (Freeley and Steinberg 2005, p. 189). ${ }^{6}$

3. Plan (cure): 'Would the action suggested by the resolution eliminate the inherent problem?'

4. Practicality: 'Is it reasonable to assume that the plan implied by the resolution could be implemented if it were found desirable?'

5. Advantages-disadvantages (cost): 'Would plans suggested by the proposition be free from detrimental side effects if they were put into effect?'

6. Counterplan: 'Is the policy stated in the proposition the best way to eliminate the problem?'

These stock issues seem all relevant to Parliamentary debate, save for the inherency stock issue. The definition of this stock issue is often vague and debate textbooks are not always in agreement about its use. According to one interpretation of the inherency stock issue the problem should be caused by the current legislation or policy (the status quo). This may be an interesting issue in academic debate but it is not very likely that this will ever play a role in legislative debates in the European

\footnotetext{
5 The idea of stock issues was introduced by Shaw (1916), who identified fourteen issues for propositions of policy. That list has since been reduced to four to six issues (van Eemeren et al. 2014, p. 432). Ihnen (2012) takes the traditional four issues as her starting point for her analysis of legislative debate in the British Parliament.

${ }^{6}$ See for a more detailed account of the inherency stock issue Ihnen (2012, pp. 42-44).
} 
Parliament. For this reason I choose not to use the inherency stock issue in my attempt to come an inventory of critical questions.

It is quite easy to relate the remainder of the stock issues to the premises in the initial practical argumentation. Stock issue 1 (problem or need) is related to premise 1a (there is a problem) in complex problem-solving argumentation. Stock issue 3 (plan) is related to premise $1 \mathrm{~b}$. (implementation of the proposal will solve the problem). And, finally, stock issue 4 (practicality), stock issue 5 (advantagesdisadvantages) and stock issue 6 (counterplan) are all related to the connecting premise 1.1a-1.1b' (Proposed legislation [of type X] that solves the problem [of type Y] should be adopted).

This means that we can list the following critical questions for pragmatic argumentation and complex problem-solving argumentation:

1. Is there a significant problem?

2. Will the legislative proposal solve the problem?

3. Is the proposal feasible?

4. Are there disadvantages?

5. Are there better means to solve the problem?

In order to answer these critical questions or in order to anticipate doubt directly prompted by these critical questions, the protagonist has to provide argumentation that backs up the specific premise under attack. The next question therefore is: what kind of argumentation can in principle be used to anticipate this kind of criticism? In the following, I would like to make an provisional inventory of the argument schemes that can be used to support the different parts of complex problem-solving argumentation.

Argumentation that can be used to support the premise stating that there is a problem

As explained, the problem statement is complex, since it includes an existential and a normative presupposition. The existential presupposition that a certain situation exists can be defended by a whole range of argument schemes, such as:

- Causal argumentation from cause to effect: 'situation $\mathrm{x}$ will occur because $\mathrm{y}$ will occur and y leads to $\mathrm{x}$ '

- Causal argumentation from effect to cause: 'situation x exits because y exists and $\mathrm{y}$ only can be caused by $\mathrm{x}$ (or is probably caused by $\mathrm{x}$ )'

- Argumentation from authority: 'situation x exists because authority y says so' or 'situation $\mathrm{x}$ exists because that is what the official data $\mathrm{y}$ indicate'

- Argumentation by example: 'situation x exists because of example y'

The normative presupposition that situation $\mathrm{x}$ is unwanted can only be supported by causal argumentation:

- Causal argumentation from cause to effect: 'situation $\mathrm{x}$ is troublesome because it leads to problematic situation y' 
It may seem that the normative presupposition can also be supported by other types of argumentation such as argumentation from authority but this is not really the case. Argumentation from authority can be used to support the causal claim that is put forward to defend the normative presupposition. This causal claim, however, may not be expressed so that it looks like argumentation from authority or other types of argumentation are directly relevant to the normative presupposition.

Argumentation that can be used to support the premise that the proposal solves the problem

The causal claim that the implementation of the new legislation will solve the problem is a particular statement; it is not a general causal statement that expresses a general causal principle such as the connecting premise in causal argumentation (causes of type $\mathrm{x}$ lead to effects of type $\mathrm{y}$ ). However, the particular causal statement ( $\mathrm{x}$ will lead to $\mathrm{y}$ ) can be supported by the general one (causes of type $\mathrm{x}$ will lead to effects of type y). It can be expected that in practice arguers will not explicitly state this general claim. Therefore this intermediating step will remain unexpressed in the argumentation. To keep things simple I take it that the causal claim can be interpreted as both particular as general. ${ }^{7}$

The particular causal claim can be defended by causal argumentation, argumentation from authority and descriptive analogy:

- Argumentation from authority: 'the proposed legislation $\mathrm{x}$ will solve the problem because authority y says so' or 'the proposed legislation $\mathrm{x}$ will solve the problem because that is what official data y indicate'

- descriptive analogy: 'the proposed legislation $\mathrm{x}$ will solve the problem because a similar measure $y$ solved the problems in a similar situation'

- symptomatic argumentation: 'the proposed legislation $\mathrm{x}$ will solve the problem $\mathrm{y}$ because, in general, events of type $\mathrm{x}$ will lead to events of type $\mathrm{y}$ '

In addition, the general causal claim that events of type $\mathrm{x}$ will lead to events of type y can be defended by argumentation by example:

- argumentation by example: 'events of type $x$ (the implementation of the proposal will lead to events like $y$ (solving the problem) because the same happened in example $\mathrm{z}$.

\section{Argumentation that can be used to support the connecting premise}

The connecting premise is directly related to the following critical questions:

1. Is the proposal feasible?

2. Are there weighty disadvantages?

\footnotetext{
7 The distinction between general and particular propositions is of importance when it comes to the choice between supporting types of argumentation. Particular propositions can be supported by descriptive analogy argumentation, while general propositions can be supported by argumentation by example.
} 
3. Are there better means to solve the problem?

In this case it is much harder to list candidates for argument schemes that can be used in support of the premise. The reason for this is that the questions are quite general. They should be specified to in order to find the types of arguments the arguer can rely on when reacting to the questions. An opponent attacking a legislative proposal will, for instance, not only claim that this proposal is not feasible, he or she will also show why it is not feasible. These critical questions can be used to specify the possible counter arguments the opponents of the plan are likely to put forward.

\section{Argumentation Used to Attack Problem-Solving Argumentation}

MEP's who attack the initial problem-solving argumentation are most probably opponents of the legislative proposal. Following the list of stock issues discussed in Sect. 4 they can use the following main arguments for the standpoint that the proposed legislation should not be adopted:

1. There is no serious problem.

2. The proposed legislation does not solve the problem.

3. The proposal is not feasible.

4. There are weighty disadvantages (the proposal has negative side-effects).

5. There are better means to solve the problem.

Argumentation that can be used to support the premise stating that there is no problem

The opponent denying that there is a problem can try to show that the existential presupposition is unacceptable which boils down at showing that the claims made by the opponent about the existence of a certain situation are wrong. It is very hard to list the types of argument schemes that can be used to show this. The opponent can also try to show that the normative presupposition is unacceptable. He can do so by showing that the negative consequences of the problematic situation will not occur or will not be negative.

The normative presupposition that situation $\mathrm{x}$ is unwanted can only be attacked by symptomatic argumentation:

- symptomatic argumentation: "situation $\mathrm{x}$ is not troublesome because it does not leads to problematic situation y'.

Argumentation that can be used to support the premise stating that the legislation does not solve the problem 
- argumentation from authority: 'the proposed legislation $\mathrm{x}$ will not solve the problem because authority y says so' or 'the proposed legislation $\mathrm{x}$ will not solve the problem because that is what official data y indicate'

- descriptive analogy: 'the proposed legislation $\mathrm{x}$ will not solve the problem because a similar measure y did not solve the problems in a similar situation'

Argumentation that can be used to support the premise stating that the proposal is not feasible

The proposal cannot be feasible because of a great many reasons. That makes is harder to mention a possible supporting type of argument. However, symptomatic argumentation seem to be the most likely candidate:

- symptomatic argumentation: 'the proposal is not feasible because it is not in line with the current legislation' or 'the proposal is not feasible because it is too expensive'

Argumentation that can be used to support the premise stating that there are weighty disadvantages

Pointing to disadvantages means pointing at side-effects; the arguer makes a causal claim. This causal claim can be defended by means of argumentation from authority and argumentation by analogy:

- Argumentation from authority: 'the proposed legislation $\mathrm{x}$ will have weighty disadvantages because authority y says so' or 'the proposed legislation $\mathrm{x}$ will not solve the problem because that is what official data y indicate'

- Descriptive analogy: 'the proposed legislation x will have weighty disadvantages because a similar measure y came with weighty disadvantages as well'

Argumentation that can be used to support the premise statingthat there are better means to solve the problem

Pointing at alternative solutions involves an argumentation pattern consisting of coordinative argumentation: the problem will be solved by an alternative measure (causal claim) and this measure is better than the original proposal (symptomatic argumentation)

\section{Prototypical Argumentative Patterns}

Based on the inventory of types of arguments that in principle can be used to defend parts of the initial practical argumentation or to defend criticisms of the initial practical argumentation, it is possible to make a choice from this list in other to establish what kind of argumentation is most likely to be found in the plenary debates in European Parliament and what kind of argumentative patterns are to be 
expected. Since there is no official regulation when it comes to the use of types of arguments this (incomplete) investigation of prototypical argumentative patterns is based on strategic consideration of the MEP's when choosing their argumentation for a certain purpose.

For a number of reasons it seems more likely that the proponents of a proposal defend the claim that there are serious problems than that they go into the matter of the effectiveness of the proposal or start defending the connecting premise (feasibility, disadvantages, alternative proposals). In other words, the opponents will rather deal with the problem than with the causal claim.

The first reason is that in a political situation it is of primary importance to show that new legislation is absolutely necessary. This will be the case in national parliaments but also in the European Parliament where there are persistent voices against more regulation and bureaucracy. Second, if there is a need to defend the causal claim, this is most like already done in the report of the Parliamentary Committee. In the report there is much more room for technicalities that are to be expected when dealing with the causal claim then in the short speaking turns of the plenary debate. These technicalities will be lost for the audiences of the debate. Third, it is easier to point at problems and there significance. Fourth, from a strategic point of view it does not seem very opportune to raise questions of feasibility, disadvantages and alternatives when these are not yet mentioned by the opponents (let sleeping dogs lie).

If an opponent tries to defend the claim that there is a problem it is most likely that he will do so by pointing at specific examples of situations in the EU in which the problems are eminent, rather than go into technicalities. The following argumentative pattern comes into being when using argument by example:

1 The proposed legislation should be adopted

1.1a There is a problem

1.1b Implementation of the proposal will solve the problem

1.1a.1 Argumentation by example

MEPs in support of a proposal often try to underline the seriousness of the problem (and therefore of the desirability of the results the proposal will bring about) by using arguments from example which are structured coordinatively. In a debate about clear labels for fruit juices sold in Europe (13 December, 2012), Carl Schlyter, for instance, defended a proposal for clearer labelling of fruit juices in the following way:

\section{December 2011, Carl Schlyter, Verts/ALE (European Green)}

Mr President, I would like to thank everyone involved in the negotiations. At times, the negotiations were rather amusing. It could be considered strange that we have spent so many hours on such a limited subject as fruit juices, but at the same time, it was question of rather important principles. Should we maintain the EU's high standard, where one exists, as opposed to the standard incorporated into international agreements? If we are to have a properly functioning single market, we must stop deceiving consumers. 
During the negotiations, I brought these juice cartons with me and I am still bringing them with me right to the bitter end. Here is one example of juice packaging: high quality, full of lovely cranberries. The problem is that cranberries are not the main ingredient of the juice-it is apple. However, I do not see apple mentioned on the packaging or in the name. This is a product from France.

Here I have a product from Sweden/Finland. It is called raspberry/blueberry and there are raspberries and blueberries on the packaging. Hidden behind an enormous blueberry there is a very tiny apple. This is misleading, because this juice consists mostly of apple-it contains 10 times as much apple as raspberry and blueberry. Here is another fruit drink that is also sold on the European market. It has lovely strawberries and passion fruit on the packaging, but what do you think is the dominant fruit? It is apple, of course. Here is another one that is sold in six other countries in Europe. It states strawberry here, but do you think it contains any strawberries? Yes, it contains a very small amount of strawberries, but as usual it is mostly apple, and the apple on this packaging is hidden behind a symbol so that you can barely see it. This is misleading and fraudulent, and we are at last doing something about it. This is what I have been fighting for, and I am very pleased that this was the end result.

This is complex problem-solving argumentation in which the arguer defends the claim that there is a problem by using arguments by example. The argumentative pattern is in this case slightly more complex:

1 The proposed legislation should be adopted

1.1a there is a problem with food labelling in Europe

$1.1 \mathrm{~b}$ Adopting the proposed legislation will solve the problem

1.1a.1a On a great many labels, the ingredients are not indicated properly

[existential premise]

1.1a.1b This misleading and fraudulent [normative presupposing]

1.1a.1a.1a-n products from Sweden/Finland, a fruit drink sold on the EU market, etc.

Just as it is to be expected that the proponents rather deal with the problem, the opponents are expected to focus on the causal claim on negative side effects and on alternative solutions. Again, these expectations have to do with the strategic choices presumably made by the MEP's when select their arguments from the topical potential. It is not very likely that the opponents will attack the problem statement, because in most cases the commission and the parliamentary committee most likely made sure that there actually is a problem and that this problem is serious enough to take action.

It is much easier for the opponents to attack the proposal itself. Since the proposal has not been implemented yet there will always exist some uncertainty about its 
effectiveness. For the same reason, the opponents may want to point at negative side-effects or present a counterplan.

A specific argumentative pattern comes into being when an opponent puts forward argumentation to support the standpoint that the proposal should not be adopted because it is not effective:

\section{The proposed legislation should not be adopted \\ 1.1 The proposed legislation does not solve the problem}

A case in point is the following contribution by Georges Bach in a debate about a European railway regulation.

\section{November, 2011 Georges Bach, EPP (European People's Party)}

Madam President, Commissioner, I would like to start by thanking the rapporteur and all the speakers for their work on this report.

Above all, this document will consolidate the powers of national regulators responsible for overseeing the correct application of rules by railway undertakings and providing non-discriminatory access to infrastructure.

Realistically, however, this document will not resolve all the sector's problems. The quality of customer service and safety should be a key focus. In addition to fair conditions of competition, there is an urgent need for investment in infrastructure and equipment, for an increase in rolling-stock capacity, for the simplification of procedures, for technical interoperability on a European level, as well as for improved technical and social conditions. Yet, unfortunately, we are currently seeing the opposite trend in many countries: services and connections are being cancelled, stations are being closed and the number of jobs in the sector is falling.

This is certainly not in keeping with the ideological vision of full liberalisation which we are working towards.

In this example the argumentative pattern is extended by complex argumentation, resulting in coordinatively structured support:

1 The proposed legislation should not be adopted

1.1 The proposed legislation does not solve the problem

1.1.1a The proposed legislation only solves part of the problem

1.1.1b The proposed legislation does not solve an import part of the problem

Opponents also regularly present argumentation in which consequences are mentioned that are counterproductive to the proclaimed objective of the proposal:

1 The proposed legislation should not be adopted

1.1 The proposed legislation will have consequences that are counterproductive

An example is João Ferreira's argumentation against measures that should strengthen the bargaining power of dairy farmers (14 February, 2012): 
14 February, 2012 João Ferreira, GUE/NGL (United Left/Nordic Green Left [...] this proposal for a regulation does not resolve the fundamental problems in the dairy sector. It is a further step down the path of excusing the unacceptable and disastrous decision to abolish milk quotas in 2015 and that alone makes it already unacceptable. The rest is a fantasy that those preparing to approve this proposal have been selling to milk producers, whose situation is deteriorating by the day. It is fantasy that it is possible to guarantee producers fair prices in the free and deregulated market that they advocate. It is fantasy that the right of every country to produce as much as it needs can be guaranteed without instruments for regulating production. It is complete fantasy. This path will boost the power of big business; of the major retailers and processing companies. It will further concentrate production with a few producers and countries, destroying it in other countries, where many producers will be ruined. It will continue to facilitate dumping between Member States and the flooding of national markets with imported milk. It will continue to promote intensive, export-orientated production that jeopardises food security and quality and environmental sustainability. For all these reasons, what is actually needed is to reconsider reviewing the abolition of dairy quotas and their adaptation to the needs of each country and to the relative level of development of its productive capacity. It is important to have market regulation and intervention instruments that guarantee producers fair prices, taking production costs and retail prices into consideration, so that value added is distributed fairly along the sector's value chain.

In their argumentation opponents may also point at possible negative side effects of implanting the legislative proposal. When they support the claim about negative side- effects by way of analogy argumentation the following argumentative pattern comes into being:

1 The proposed legislation should not be adopted

$1.1 \quad$ Implementing of the proposal leads to negative side-effects

1.1.1 This also happened in a similar situation

An example of this pattern is provided by Catherine Grèze, rapporteur for the opinion of the Committee on Development, in a debate in the European Parliament held on 20 November, 2012. This debate is about the environmental impact of shale gas and shale oil extraction activities. Ms Grèze:

\section{November 2012, Catherine Grèze, Rapporteur for the Opinion of the Committee on Development}

I am absolutely against the extraction of shale gas. [...] Imagine yourselves what the consequences could be, and how devastating they could be, in developing countries where access to water is vital. But the extraction of shale gas is also about land grabbing and poor land quality; in other words, it brings into question food sovereignty in many countries. Therefore, ladies and gentlemen, despite the publicity, despite the brazen lobbying that has been carried out even at the very door of the hemicycle, I would urge you to 
shoulder your responsibilities.[...] I saw an excellent film, Gasland, which is worth seeing, and which showed the truly dramatic consequences, no pun intended, on water resources and human and animal health in the United States, which as you know is a highly developed and technologically advanced country.

Grèze points in her argumentation at the negative consequences of shale gas exploitation for water resources. She then defends the causal claim involved in this argument by comparing exploiting shale gas in developing countries with the exploitation of shale gas in the United States. ${ }^{8}$

Another type of argumentation used to support the premise that there are sideeffects is argument by example. The argumentative pattern is as follows:

1 The proposed legislation should not be adopted

1.1 Implementing of the proposal will lead to negative effects

1.1.1 Examples $\mathrm{x}-\mathrm{n}$ make this clear

In his argumentation Evžen Tošenovský for the standpoint that the new EU energy policy should not be adopted, Evžen Tošenovský points at a specific negative side effects and he gives an example (excessive support to solar power) to support his claim:

\section{April 2012, Evžen Tošenovský, ECR Group (European Conservatives and Reformists)}

Mr President, the directive submitted is an important part of the key debate on EU energy policy. The submitted draft again, unfortunately, involves heavy administrative intervention in the energy sector. With the current preferenceand the sometimes exaggerated direct financial support-for renewables, the situation on the market may get even worse. In some countries, for example, we have seen excessive support for solar power, with long-term commitments to purchase electricity at inflated prices. [...]. I am therefore concerned about this heavy regulatory intervention, which may lead to a downturn in manufacturing opportunities in many countries, and may also have significant and incalculable social effects in Member States. Overall, this may put at risk the global competitiveness of the EU.

Another argumentative pattern that is likely to occur, comes into being when an opponent of legislation points at an alternative solution and supports the premise that this alternative is better by making clear that it is more likely to be effective:

1. The proposed legislation should not be adopted

1.1 There is a better alternative

1.1.1a The proposed legislation does not solve the problem

1.1.1b The alternative solution will solve the problem

\footnotetext{
${ }^{8}$ By her addition that the United States is a highly developed and technologically advanced country the analogy argumentation becomes a fortiori.
} 
An example is provided by Jacky Hénin, who is convinced that there is a problem with the European energy security and that changes are necessary, but who nonetheless does not agree with the proposal for a pan-European energy policy.

\section{September 2010, Jacky Hénin, GUE/NGL (European United Left-Nordic Green Left)}

Mr President, do we need to ensure energy security and independence? Yes we do. However, to fully ensure security and independence, it is essential that we remove gas and other energy sources from the serious problems caused by speculative markets, declaring them public assets, and enter into tariff agreements that respect the people of producer countries and provide security for European consumers. [...] Unlike our rapporteur, I am not convinced that the free action of the market and private companies operating in the gas industry will secure gas supplies in the Union. To guarantee gas supplies for all citizens of the Union we need to nationalize the large gas groups and create, out of these entities, a European interest group under multinational and, above all, public control.

\section{Conclusion}

Argumentation in parliamentary debate evolves around problem-solving pragmatic argumentation or complex problem-solving argumentation. In order to give an idea of the possible argumentative patterns that may occur in the parliamentary debate, I made an inventory of types of argument schemes arguments that may be used by MEP's to defend or attack the original pragmatic argumentation put forward. From that inventory I selected the argument schemes that most likely will be used by MEP's, forming prototypical argumentative patterns.

The opponents in parliamentary debate are expected to focus on the fact that there is a problem that needs to be solved. They will argue that there is a problem and they will try to make clear that the problems are serious. They will do so by showing that the problems are widespread or numerous. The opponents, on the other hand, will focus on causal premise: they are more likely to cast doubt on the statement that the proposal will solve the problem, or they will point at possible alternative solutions. This leads automatically to other argumentative patterns.

Prototypical argumentative patterns used by the proponents of a plan consists of problem-solving pragmatic argumentation or complex problem-solving argumentation that is supported by means of argumentation by example. Prototypical argumentative patterns used by the opponents of the plan involve argumentation showing that the plan is not effective or that it has serious side effects or that there are much better alternative solutions.

In this paper I made an investigation of the prototypical argumentative pattern put forward by the rapporteur and by MEP's. The question remains whether these prototypical patterns are all stereotypical. Another question is, of course, whether there are more stereotypical patterns. Based on the inventory of possible supporting types of argument that I have presented here, systematic empirical research needs to 
be carried out in order to find the stereotypical argumentative patterns occurring in legislative debate in the European Parliament.

Open Access This article is distributed under the terms of the Creative Commons Attribution 4.0 International License (http://creativecommons.org/licenses/by/4.0/), which permits unrestricted use, distribution, and reproduction in any medium, provided you give appropriate credit to the original author(s) and the source, provide a link to the Creative Commons license, and indicate if changes were made.

\section{References}

Corbett, R., F. Jacobs, and M. Schackleton. 2007. The European Parliament. London: John Harper Publishing.

Freeley, A.J., and D.L. Steinberg. 2005. Argumentation and debate. Critical thinking for reasoned decisions making. Boston: Wadsworth.

Ihnen Jory, C. 2012. Pragmatic argumentation in law-making debates. Instruments for the analysis and evaluation of pragmatic argumentation at the Second Reading of the British parliament. Amsterdam: Sic Sat.

Klopf, D.W., and J.C. McCroskey. 1969. The elements of debate. New York: Arco.

Shaw, W.C. 1916. Systematic analysis of debating problems. Journal of Speech Communication 2: 344-351.

van Eemeren, F.H. 2010. Strategic maneuvering in argumentative discourse. Extending the pragmadialectical theory of argumentation. Amsterdam-Philadelphia: John Benjamins.

van Eemeren, F.H., and B. Garssen. 2010. In varietate concordia-United in diversity: European parliamentary debate as an argumentative activity type. Controversia 7(1): 19-37.

van Eemeren, F.H., and B. Garssen. 2011. Exploiting the room for strategic maneuvering in argumentative discourse. Dealing with audience demand in the European Parliament. In Exploring argumentative contexts, ed. F.H. van Eemeren, and B. Garssen. John Benjamins: AmsterdamPhiladelphia.

van Eemeren, F.H., B. Garssen, E.C.W. Krabbe, A.F. Snoeck Henkemans, B. Verheij, and J.H.M. Wagemans. 2014. Handbook of argumentation theory. Dordrecht etc.: Springer. 